Original Article

\title{
DIALYSIS PRACTICE PATTERN IN PATIENTS UNDERGOING HEMODIALYSIS IN A TERTIARY AND A PRIVATE HOSPITAL
}

\section{DHANISHA PRAMOD NERURKAR ${ }^{1}$, JANET MARY OOMMEN ${ }^{1}$, MANJUSHA SAJITH1* ${ }^{*}$, DR. SUNIL JAWALE², DR. SHRINIVAS AMBIKE ${ }^{2}$}

1Department of Clinical Pharmacy, Bharati Vidyapeeth Deemed to be University, Poona College of Pharmacy, Pune, ${ }^{2}$ Department of Nephrology, Bharati Hospital and Research Center, Pune, ${ }^{2}$ Department of Nephrology, Jehangir Hospital, Pune

Email: manjusaji1@yahoo.com

Received: 06 Mar 2019 Revised and Accepted: 02 May 2019

\section{ABSTRACT}

Objective: To evaluate the dialysis practice pattern in chronic kidney disease patients undergoing hemodialysis in a tertiary and a private hospital

Methods: A prospective observational study of six months duration was carried out in 158 CKD patients on hemodialysis for a minimum period of one month. Data such as socio-demographic, clinical characteristics and dialysis practice details were captured from the patient's medical records into the pre-designed Patient Proforma. The collected data were analysed.

Results: Majority of respondents were male (67.09\%), more than 60 y of age (32.28 \%), married (89.24\%). Hypertension (26.51\%, 17.33\%) was found to be the leading cause of CKD in a tertiary and private hospital. In the tertiary hospital, $78.31 \%$ of patients were undergoing twice-weekly hemodialysis, whereas in the private hospital thrice weekly (50.67\%) hemodialysis was common. About $51.81 \%$ of patients in the tertiary and $58.67 \%$ in the private hospital was undergoing hemodialysis for 1-5 y with Arterio-Venous Fistula (59.04\%, 94.67\%) as the permanent vascular access $(P<0.001)$

Conclusion: This study shows that hypertension was the leading cause of CKD in both hospitals. In the tertiary hospital twice weekly hemodialysis with arteriovenous fistula (AVF) and Permanent Catheter (IJV), were both preferred as the permanent vascular access. Whereas in the private hospital majority were undergoing thrice weekly hemodialysis and AVF was highly preferred.

Keywords: Dialysis practice pattern, Chronic Kidney Disease, Hemodialysis

(C) 2019 The Authors. Published by Innovare Academic Sciences Pvt Ltd. This is an open-access article under the CC BY license (http://creativecommons.org/licenses/by/4.0/] DOI: http://dx.doi.org/10.22159/ijpps.2019v11i6.32943

\section{INTRODUCTION}

Chronic kidney disease (CKD) has become a public health problem worldwide. The global prevalence of CKD Stages 1 to 5 was $13 \cdot 4 \%$ [1]. Whereas the prevalence in India was $17.2 \%$ [2]. The global prevalence of end stage renal disease patients on dialysis was $215 /$ million population [3]

Dialysis practice pattern is a prospective observational study of hemodialysis practices based on the collection of data from a random sample of patients across various dialysis facilities. These samples help us to obtain a better understanding of the variation in practice patterns across different facilities. Studies have shown improved patient survival with higher dialysis dose and different dialysis membrane, thereby concluding that dialysis outcome can be modified by changes in dialysis practice [4]. Therefore, our study focuses on the dialysis practice pattern in patients undergoing hemodialysis in a tertiary and a private hospital.

\section{MATERIALS AND METHODS}

A prospective observational study was carried out from August 2017 to April 2018 in a tertiary hospital and private hospital. Patients having CKD and on maintenance haemodialysis, for at least $>1$ mo was included in our study. Pregnant women on dialysis, age less than $18 \mathrm{y}$, patients who are being dialysed for Acute Kidney Injury and patients who are being evaluated for renal transplantation were excluded. Ethical approval was obtained for the study from the institutional ethics committee (BVDUMC/IEC/84) and the patient's informed consent was taken prior to the study. The details like age, gender, educational and employment status, social history, comorbid conditions, frequency of dialysis, duration of dialysis, pre-and postdialysis weight, blood pressure, vascular access, and laboratory values were noted in the self-pre-designed Patient Proforma. mean \pm standard deviation and percentages was used for summarizing the data, other relevant statistical tests Chi-square test was used for quantitative data and comparison of proportions. The $P$ value $<0.05$ was considered as statistical significant

\section{RESULTS}

A total of 158 patients from two hospitals in Pune were included. Out of which, 83 and 75 patients were from a tertiary and a private hospital respectively, satisfying the inclusion criteria. The mean age of the patients undergoing hemodialysis in these two hospitals were $49.53 \pm 15.09 \mathrm{y}$ and $51.52 \pm 14.53 \mathrm{y}$, out of which majority were greater than $46 \mathrm{y}(63.29 \%)$. The highest number of patients undergoing hemodialysis in both the hospitals was males $(73.49 \%$ $60 \%$ ). Majority of the patients in the private hospital were from the middle socioeconomic class $(80 \%)$ whereas, in the tertiary hospital subjects belong to lower-middle socioeconomic class (100\%) which was found to be statistically significant $(P=<0.001)$. Highest number of patients were unemployed $(50.60 \%, 36 \%)$, married $(90.36 \%$, $88 \%)$ and obtained high school education $(62.65 \%, 45.33 \%)(P$ $=<0.001)$. About $78(93.98 \%)$ patients were covered with insurance or health scheme in the tertiary hospital and only $39(52 \%)$ were insured in the private hospital [table 1]

Hypertension was the common comorbidity among hemodialysis patients in both the hospitals [table 2]. Mean pre and post dialysis blood pressure (systolic and diastolic) were similar in the tertiary hospital (154.30 \pm 24.12 and $89.41 \pm 13.96 \mathrm{~mm} \mathrm{Hg}$ ) whereas in the private hospital the pre-dialysis systolic and diastolic blood pressure were $151.82 \pm 28.01$ and $78.78 \pm 14.06 \mathrm{~mm} \mathrm{Hg}$ and the post dialysis systolic and diastolic blood pressure were $149.4 \pm 27.77$ and $80.63 \pm 13.43 \mathrm{~mm} \mathrm{Hg}$, respectively. 
Sajith et al.

Int J Pharm Pharm Sci, Vol 11, Issue 6, 72-76

Table 1: Socio-demographic characteristics of chronic kidney disease patients undergo hemodialysis

\begin{tabular}{|c|c|c|c|}
\hline \multirow[t]{2}{*}{ Characteristics } & \multicolumn{2}{|l|}{ Number of patients (\%) } & \multirow[t]{2}{*}{ Total $(n=158)$} \\
\hline & Tertiary hospital $(\mathrm{n}=83)$ & Private hospital $(n=75)$ & \\
\hline \multicolumn{4}{|l|}{ Gender } \\
\hline Male & $61(73.49)$ & $45(60)$ & $106(67.09)$ \\
\hline Female & $22(26.51)$ & $30(40)$ & $52(32.91)$ \\
\hline \multicolumn{4}{|l|}{ Age (years) } \\
\hline $18-31$ & $11(13.25)$ & $7(9.33)$ & $18(11.39)$ \\
\hline $32-45$ & $22(26.51)$ & $18(24)$ & $40(25.32)$ \\
\hline $46-59$ & $25(30.12)$ & $24(32)$ & $49(31.01)$ \\
\hline$\geq 60$ & $25(30.12)$ & $26(34.67)$ & $51(32.28)$ \\
\hline \multicolumn{4}{|c|}{ Socioeconomic class (based on monthly income) } \\
\hline Lower & $30(36.14)$ & $5(6.67)$ & $35(22.15)$ \\
\hline Lower middle & $7(8.43)$ & $8(10.67)$ & $15(9.49)$ \\
\hline Middle & $46(55.42)$ & $60(80)$ & $106(67.09)$ \\
\hline Upper middle & $0(0)$ & $1(1.33)$ & $1(0.63)$ \\
\hline Higher & $0(0)$ & $1(1.33)$ & $1(0.63)$ \\
\hline \multicolumn{4}{|l|}{ Educational status } \\
\hline Illiterate & $14(16.87)$ & $2(2.67)$ & $16(10.13)$ \\
\hline Primary School & $3(3.61)$ & $4(5.33)$ & $7(4.43)$ \\
\hline High School & $52(62.65)$ & $34(45.33)$ & $86(54.43)$ \\
\hline Graduate & $14(16.87)$ & $29(38.67)$ & $43(27.22)$ \\
\hline Post Graduate & $0(0)$ & $6(8)$ & $6(3.80)$ \\
\hline \multicolumn{4}{|l|}{ Employment Status } \\
\hline Employed & $24(28.92)$ & $24(32)$ & $48(30.38)$ \\
\hline Unemployed/Retired & $59(71.08)$ & $51(68)$ & $110(69.62)$ \\
\hline \multicolumn{4}{|l|}{ Marital Status } \\
\hline Married & $75(90.36)$ & $66(88)$ & $141(89.24)$ \\
\hline Unmarried & $8(9.64)$ & $9(12)$ & $17(10.76)$ \\
\hline \multicolumn{4}{|c|}{ Medical Insurance/Health scheme } \\
\hline Insured/Health scheme & $78(93.98)$ & $39(52)$ & $117(74.05)$ \\
\hline Non-Insured & $5(6.02)$ & $36(48)$ & $41(25.95)$ \\
\hline
\end{tabular}

Hypertension was found to be the leading cause of chronic kidney disease in the tertiary (26.51\%) and the private hospital (17.33\%) [fig. 1].

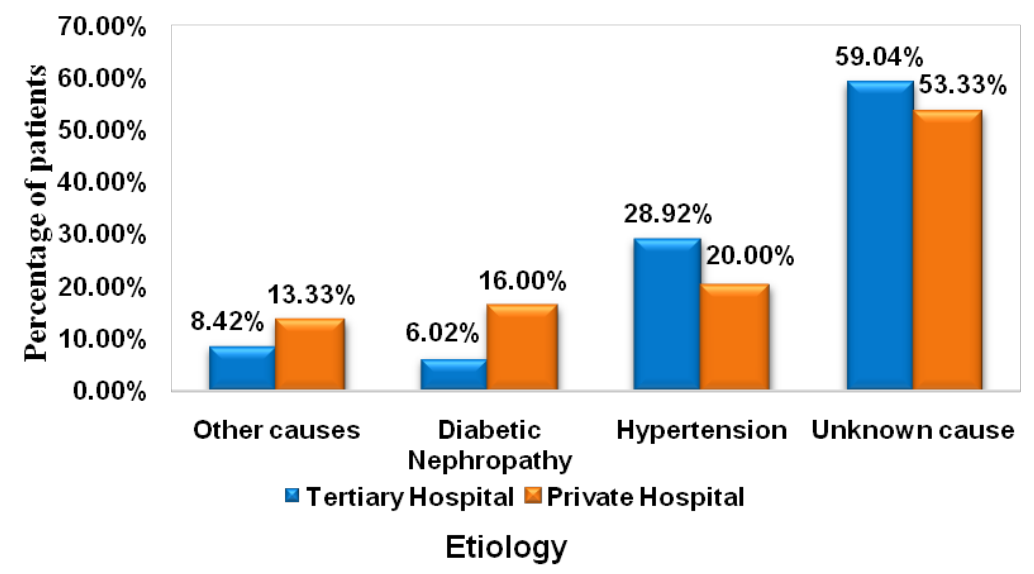

Fig. 1: Etiology of chronic kidney disease patients undergoing hemodialysis in a tertiary and a private hospital

Table 2: Co-morbidities of chronic kidney disease patients undergoing hemodialysis

\begin{tabular}{llll}
\hline Characteristics & Number of patients (\%) & & Total (n=144) \\
\cline { 2 - 4 } & Tertiary hospital (n = 80) & Private hospital (n = 64) & Chi-square \\
\hline Co-morbid Condition & & & 0.909 \\
Present & 80 & 64 & 0.340 \\
Absent & 3 & 6 & $81(56.25)$ \\
Hypertension & $46(57.5)$ & $35(54.69)$ & $48(33.33)$ \\
Diabetes+Hypertension & $28(35)$ & $20(31.25)$ & $5(3.47)$ \\
Diabetes Mellitus & $0(0)$ & $5(7.81)$ & $2(1.39)$ \\
Hypothyroidism/Hyperthyroidism & $0(0)$ & $2(3.13)$ & $3(2.08)$ \\
Hypertension+Hypothyroidism & $3(3.75)$ & $0(0)$ & $1(0.69)$ \\
Hypertension+Diabetes+Coronary artery & $1(1.25)$ & $0(0)$ & $1(0.69)$ \\
disease+Hypothyroidism & $1(1.25)$ & $0(0)$ & $2(1.39)$ \\
Hypertension+Diabetes+Coronary artery disease & $1(1.25)$ & $1(1.56)$ & $1(0.69)$ \\
Hypertension+Coronary artery disease & $0(0)$ & $1(1.56)$ & \\
Hypertension+Diabetes+COPD & & & \\
\hline
\end{tabular}


Table 3 shows that the Internal Jugular Vein (IJV) catheter was the initial vascular access in both the hospitals. In both the groups, Arterio-Venous Fistula (AVF) was the permanent vascular access in the majority of the patients $(59.04 \%, 94.67 \%) .78 .31 \%$ of the patients in the tertiary hospital were undergoing twice-weekly hemodialysis, whereas in the private hospital there were an equal number of patients undergoing twice $(48.00 \%)$ and thrice $(50.67 \%)$ weekly hemodialysis.

Table 3: Vascular access patterns of chronic kidney disease patients undergoing hemodialysis

\begin{tabular}{lllc}
\hline Characteristics & Number of patients (\%) & \multicolumn{1}{c}{$\begin{array}{l}\text { Total } \\
\text { (n=158) }\end{array}$} & \multicolumn{1}{c}{ Chi-square value } \\
\cline { 2 - 4 } & Tertiary hospital (n=83) & Private hospital (n=75) & \\
\hline $\begin{array}{l}\text { Vascular access } \\
\text { Access at the initiation of MHD }\end{array}$ & & & $158(100)$ \\
$\begin{array}{l}\text { Internal Jugular vein Catheter } \\
\text { Access while on MHD }\end{array}$ & $83(100)$ & $71(94.67)$ & $120(75.95)$ \\
$\begin{array}{l}\text { Arterio-Venous Fistula } \\
\text { Permanent Catheter (IJV) }\end{array}$ & $49(59.04)$ & $4(5.33)$ & 27.38 \\
\hline
\end{tabular}

Chi-square test, ${ }^{*} \mathrm{P}<0.05$ is considered to be statistically significant

The average duration of hemodialysis in both the centers was $4 \mathrm{~h}$. About $51.81 \%$ of patients in the tertiary and $58.67 \%$ in the private hospital was undergoing hemodialysis for 1-5 y [table 4]. Nearly all the patients were vaccinated for Hepatitis B virus (HBV). About 7 (9.33\%) patients had Hepatitis $C$ virus infection in the private hospital.

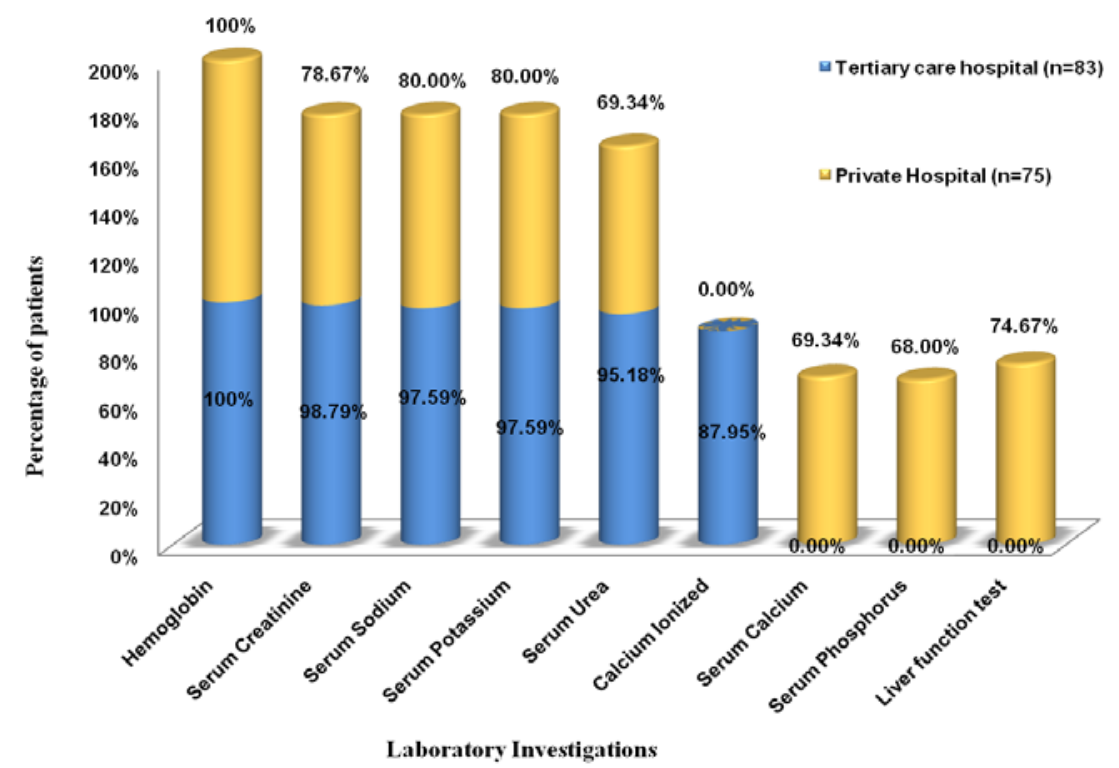

Fig. 2: Laboratory tests performed in chronic kidney disease patients undergoing hemodialysis in a tertiary and a private hospital

Table 4: Dialysis-related characteristics of chronic kidney disease patients undergoing hemodialysis

\begin{tabular}{|c|c|c|c|c|c|}
\hline \multirow[t]{2}{*}{ Characteristics } & \multicolumn{2}{|l|}{ Number of patients (\%) } & \multirow{2}{*}{$\begin{array}{l}\text { Total } \\
(n=158)\end{array}$} & \multirow[t]{2}{*}{ Chi-square value } & \multirow[t]{2}{*}{$P$-value } \\
\hline & Tertiary hospital $(n=83)$ & Private hospital $(n=75)$ & & & \\
\hline Duration of dialysis per session (hrs) & $4 \mathrm{~h}$ & $4 \mathrm{~h}$ & & & \\
\hline \multicolumn{6}{|l|}{ Frequency of dialysis session per week } \\
\hline Once & $6(7.23)$ & $1(1.33)$ & $7(4.43)$ & 25.07 & $<0.001^{*}$ \\
\hline Twice & $65(78.31)$ & $36(48)$ & $101(63.92)$ & & \\
\hline Thrice & $12(14.46)$ & 38 (50.67) & $50(31.65)$ & & \\
\hline Characteristics & Number of patients $(\%)$ & & $\begin{array}{l}\text { Total } \\
(n=158)\end{array}$ & Chi-square value & $P$-value \\
\hline \multicolumn{6}{|l|}{ Duration on Dialysis } \\
\hline Less than $1 \mathrm{y}$ & $30(36.14)$ & $19(25.33)$ & $49(31.01)$ & 2.89 & 0.408 \\
\hline $1-5 y$ & $43(51.81)$ & $44(58.67)$ & $87(55.06)$ & & \\
\hline $6-10 y$ & $8(9.64)$ & 11 (14.67) & $19(12.03)$ & & \\
\hline More than $10 y$ & $2(2.41)$ & $1(1.33)$ & $3(1.90)$ & & \\
\hline \multicolumn{6}{|l|}{ Interdialytic Weight Gain } \\
\hline Less than $1 \mathrm{~kg}$ & $12(14.46)$ & $8(10.67)$ & $20(12.66)$ & 1.10 & 0.894 \\
\hline $1-2 \mathrm{~kg}$ & $18(21.69)$ & $19(25.33)$ & $37(23.42)$ & & \\
\hline $2-3 \mathrm{~kg}$ & $25(30.12)$ & $25(33.33)$ & $50(31.65)$ & & \\
\hline $3-4 \mathrm{~kg}$ & 15 (18.07) & $18(24)$ & 33 (20.89) & & \\
\hline$\geq 4 \mathrm{~kg}$ & $5(6.02)$ & $5(6.67)$ & $10(6.33)$ & & \\
\hline Nil & $8(9.64)$ & $0(0)$ & $8(5.06)$ & & \\
\hline Mean Ultrafiltration volume (ml) & $2405.31 \pm 1268.85$ & $2964.48 \pm 982.85$ & & & \\
\hline
\end{tabular}

Chi-square test, ${ }^{*} \mathrm{P}<0.05$ is considered to be statistically significant 
Hematological, serum creatinine and biochemistry tests were performed in both the hospitals, whereas serum calcium, serum phosphorus, and liver function tests were performed only in the private hospital. The mean hemoglobin value was found to be $9.47 \pm 1.35$ for tertiary hospital and $10.21 \pm 1.36$ for a private hospital. The mean of serum creatinine in the tertiary and private hospital were $6.75 \pm 2.12$ and $9.33 \pm 2.29$ respectively whereas the mean for serum sodium and serum potassium for both the hospitals were 133.69 \pm 4.01 , $4.83 \pm 0.81$ and $136.04 \pm 6.63,5.29 \pm 0.62$ respectively [fig. 2]

\section{DISCUSSION}

Chronic kidney disease refers to an irreversible loss of renal function that develops due to a multi-factorial etiology. Chronic kidney disease often goes unrecognized until its terminal complication, the end-stage renal disease develops for which patients receive any form of renal replacement therapy. Renal replacement therapy options and practice varies worldwide and is influenced by patient's choice, nephrologists practice pattern, insurance policies, and socioeconomic factors.

Majority of the patients undergoing hemodialysis were males $(67.09 \%)$ which are a consistent pattern when compared to Lakshminarayan et al. [5], Sanjay K. Agarwal et al. [6], and Manfred Hecking et al. [7], who reported similar results. Males demonstrate higher risk factors such as overweight, having a higher waist circumference, and a higher blood pressure which makes them more vulnerable to develop chronic kidney disease over a period of time [8]. On the contrary Idan Goldberg et al. [8], and Lori L. Pounds et al. [9] in their report state that the prevalence of CKD tends to be higher in women, whereas the disease progression in men is more severe. Mean age reported in the tertiary care hospital $(49.53 \pm 15.09$ y) and the private hospital $(51.52 \pm 14.53 \mathrm{y})$ was found to be similar. Bernard Canaud et al. [10], in his study states that elderly patients account for an increasing fraction of patients on renal replacement therapy worldwide due to aging and underlying co-morbidities $(25 \%-30 \%)$. Thus, justifying the higher number of our study subject belonging to the age group of greater than $46 \mathrm{y}$.

In India, hemodialysis is the dominant renal replacement therapy option and is largely influenced by the socioeconomics of the area of practice and limited insurance schemes [11, 12]. In this study patients in the private hospital were on thrice weekly hemodialysis (50.67\%), whereas in the tertiary care hospital majority were on twice weekly hemodialysis $(78.31 \%)$ considering that majority of them belonged to the lower-middle socioeconomic class, were unemployed and economically depended on their family or insurance coverage for dialysis and drug expenditure. Similar result was published by Brian Bieber et al. which justify our findings [13]. Seyed Abbas Tavallaii et al. [14]in his report stated that marital adjustment is considered as a part of social wellbeing, disturbed marital relationship adversely affects physical health, mental health, the quality of life, and even economic status of individuals which can be concurrent with our study that reported $90.36 \%$ in the tertiary care hospital and $88.00 \%$ in private hospital were married. Patients undergoing hemodialysis were independent of their social habits (smoking, alcohol consumption and tobacco chewing).

Hypertension can be a cause or a consequence of chronic kidney disease. It has been reported to occur in $85 \%$ to $95 \%$ of patients with chronic kidney disease (stages 3-5) in the U. S. [15]. Decline in kidney function is typically associated with elevated blood pressure, and sustained elevations in blood pressure thus hasten the progression of kidney failure. About $56.33 \%$ of our study population had unknown etiology as the leading cause of hypertension $(22.15 \%)$ as the second leading cause of end stage renal disease. An earlier report published by MJ Kulkarni et al. also proposed unknown etiology as the leading cause and diabetic nephropathy as the second leading cause of endstage renal disease [4]. Late diagnosis of renal failure is a worldwide phenomenon, more so in developing countries like India (65\%) [16]. Delay in early signs for detection and management, low education status and knowledge regarding conditions can be considered as major factor. Hypertension was also the major co-morbid condition among our study subjects $(95.14 \%)$ a portion of our study subject also suffered from diabetes along with hypertension (33.33\%). This study result is in good agreement with that reported by Winkelmayer WC. et al. $[17,18]$.
No difference was found between the pre and post dialysis blood pressure in both the groups. This study reported that all the patients undergoing hemodialysis were using catheter as their initial vascular access for a period of two to three months due to late referral or poor awareness and about $59.04 \%$ of tertiary care hospital and $94.67 \%$ of private hospital had arterio-venous fistula as their permanent vascular access which is similar to the result reported by Dinesh Bansal et al.[19]. Arterio-venous fistulas is generally preferred owing to its durability and the fewer associated complications [20]. Permanent Catheter was also considered as a permanent vascular access in $40.96 \%$ and $5.33 \%$ of the patients in the tertiary care hospital and the private hospital respectively. The increase in the number of patients choosing permanent catheter as the vascular access in the tertiary care hospital can depend on a lack of patient education and cost of surgery.

Hepatitis B and/or C infection while on dialysis is another major problem in the country. Availability of reasonably effective vaccination against hepatitis B has helped to reduce the rate of hepatitis B virus infection but there is no such vaccination to prevent hepatitis $C$. The prevalence is widely variable, from $<5 \%$ to $75 \%$ [15]. Very few patients from the private hospital (9.33\%) were hepatitis C positive and few developed HCV infection during their course in the hospital.

The lab tests performed in both the hospitals were haemoglobin, serum creatinine, serum sodium, serum potassium, serum urea and calcium ionized. The hemoglobin is levels are low in patients with CKD because the kidneys no longer make the hormone erythropoietin that stimulates the bones to make red blood cells (RBCs). Creatinine and other electrolytes are checked since kidneys no longer filter them properly. In addition to this, the elevated levels of toxins in the blood cause the RBCs to have a shortened life span. According to Kidney Disease: Improving Global Outcomes (KDIGO) guidelines, monitoring in CKD includes serum calcium and phosphorous for every 1-3 mo and PTH every 3-6 mo [21].

\section{CONCLUSION}

This study illustrates the present day scenario of dialysis in tertiary care and private hospital. In the tertiary hospital, the majority of the patients belonged to lower-middle socioeconomic class and were covered under insurance or health scheme. Twice weekly hemodialysis was more preferred over thrice weekly hemodialysis with AVF and Permanent Catheter (IJV), both preferred as the permanent vascular access in the tertiary hospital. Whereas, in the private hospital majority of them were from middle class undergoing thrice weekly hemodialysis and AVF was highly preferred. Hypertension was the most common cause of CKD and also the highest co-morbidity reported.

\section{LIMITATIONS OF THE STUDY}

Limitations of our study include small sample size and six months duration which provided limited data of study population. Due to prospective observational study, data was collected only once and further follow-up was not done. Information on the status of the patient's health was not available.

\section{AUTHORS CONTRIBUTIONS}

All the author have contributed equally for the designing, preparation and review of the study.

\section{CONFLICT OF INTERESTS}

\section{Declared none}

\section{REFERENCES}

1. Hill NR, Fatoba ST, Oke JL, Hirst JA, O'Callaghan CA, Lasserson DS, et al. Global prevalence of chronic kidney disease-a systematic review and meta-analysis. PloS One 2016;6:11.

2. Singh A, Farag Y, Mittal B, Subramanian K, Reddy S, Acharya V, et al. Epidemiology and risk factors of chronic kidney disease in India-results from the SEEK (Screening and early evaluation of kidney disease) study. BMC Nephrol 2013;14:114.

3. Yang F, Khin LW, Lau T, Chua HR, Vathsala A, Lee E, et al. Hemodialysis versus peritoneal dialysis: a comparison of 
survival outcomes in South-East Asian patients with end-stage renal disease. PloS One 2015;10. Doi:10.1371/journal. pone. 0140195 .

4. Kulkarni MJ, Jamale T, Hase NK, Jagdish PK, Keskar V, Patil H, et al. A cross-sectional study of dialysis practice-patterns in patients with chronic kidney disease on maintenance hemodialysis. Saudi J Kidney Diseases Transplantation 2015;26:1050.

5. Lakshminarayana G, Sheetal L, Mathew A, Rajesh R, Kurian G, Unni V. Hemodialysis outcomes and practice patterns in endstage renal disease: experience from a tertiary care hospital in Kerala. Indian J Nephrol 2017;27:51.

6. Agarwal SK, Dash SC, Irshad M, Raju S, Singh R, Pandey RM. Prevalence of chronic renal failure in adults in Delhi, India. Nephrol Dialysis Transplantation 2005;20:1638-42.

7. Hecking M, Bieber BA, Ethier J, Kautzky Willer A, SunderPlassmann G. Sex-specific differences in hemodialysis prevalence and practices and the male-to-female mortality rate: the dialysis outcomes and practice patterns study (DOPPS). PLoS Med 2014;11. Doi:10.1371/journal. pmed.1001750

8. Goldberg I, Krause I. The role of gender in chronic kidney disease. E Med J 2016;1:58-64.

9. Pounds LL, Teodorescu VJ. Chronic kidney disease and dialysis access in women. J Vascular Surgery 2013;57:49-53.

10. Canaud B, Tong L, Tentori F, Akiba T, Karaboyas A, Gillespie B, et al. Clinical practices and outcomes in elderly hemodialysis patients: results from the dialysis outcomes and practice patterns study (DOPPS). Clin J Am Soc Nephrol 2011;6:1651-62.

11. Mukherjee T, Devi G, Geetha S, Anchan N, Subbaiyan S. A comparison of practice pattern and outcome of twice-weekly and thrice-weekly hemodialysis patients. Indian J Nephrol 2017;27:185.

12. Thenmozhi P. Quality of life of patients undergoing hemodialysis. Asian J Pharm Clin Res 2018;11:219-23.

\section{Int J Pharm Pharm Sci, Vol 11, Issue 6, 72-76}

13. Bieber B, Qian J, Anand S, Yan Y, Chen N, Wang M, et al. Twotimes weekly hemodialysis in China: frequency, associated patient and treatment characteristics and quality of life in the china dialysis outcomes and practice patterns study. Nephrol Dialysis Transplantation 2013;29:1770-7.

14. Tavallaii SA, Nemati E, Vishteh HR, Farahani MA, Lankarani MM, Assari S. Marital adjustment in patients on long-term hemodialysis. Iran J Kidney Dis 2009;3:156-61.

15. Leticia Buffet, Pharm D, Charlotte Ricchetti, Pharm D, BCPS, CDE. Chronic kidney disease and hypertension: a destructive combination. US Pharm 2012;37:26-9.

16. Bhowmik D, Tiwari SC. Challenges of hemodialysis in India. J Int Med Sci Acad 2012;25:99-100.

17. Winkelmayer WC, Chang TI, Mitani AA, Wilhelm-Leen ER, Ding $\mathrm{V}$, Chertow GM, et al. Longer-term outcomes of darbepoetin alfa versus epoetin alfa in patients with ESRD initiating hemodialysis: a quasi-experimental cohort study. Am J Kidney Diseases 2015;66:106-13.

18. Dare AJ, Fu SH, Patra J, Rodriguez PS, Thakur JS, Jha P, et al. Renal failure deaths and their risk factors in India 2001-13: nationally representative estimates from the million death study. Lancet Global Health 2017;5:89-95.

19. Bansal D, Kher V, Gupta KL, Banerjee D, Jha V. Haemodialysis vascular access: current practices amongst Indian nephrologists. J Vasc Access 2018;19:172-6.

20. Goel N, Kwon C, Zachariah TP, Broker M, Folkert VW, Bauer C, et al. Vascular access placement in patients with chronic kidney disease stages 4 and 5 attending an inner city nephrology clinic: a cohort study and survey of providers. BMC Nephrol 2017;18:28.

21. Moe S, Drueke T, Cunningham J, Goodman W, Martin K, Olgaard K, et al. Definition, evaluation, and classification of renal osteodystrophy: a position statement from kidney disease: improving global outcomes (KDIGO). Kidney Int 2006;69:1945-53. 